\title{
Interação e conflito entre categorias profissionais em organizações hospitalares públicas
}

\author{
Interaction and conflict among professional \\ categories in public hospitals
}

Luís Otávio Farias 1

Jeni Vaitsman 1

\footnotetext{
1 Departamento de Ciências Sociais, Escola Nacional de Saúde Pública, Fundação Oswaldo Cruz.

Rua Leopoldo Bulhões 1480, Rio de Janeiro, $R J$

21041-210, Brasil.

farias@ensp.fiocruz.br vaitsman@ensp.fiocruz.br
}

\begin{abstract}
The article discusses some data from a study on the opinions and perceptions of the labor situation and environment among health professionals and administrative workers at the Research Center of the Evandro Chagas Hospital (CPqHEC/FIOCRUZ) in Rio de Janeiro. Certain patterns of conflict observed in the study express the distribution of power and prestige which is typical of hospitals. Many of the meanings people ascribe to their experiences within the organization are mediated by social representations originating in the broader social context to which the organization belongs.
\end{abstract}

Key words Health Manpower; Health Facilities; Organizations; Health Personnel

Resumo Com base em pesquisa realizada no Centro de Pesquisas Hospital Evandro Chagas (CPqHEC/FIOCRUZ), que investigou as opiniões e percepções dos funcionários sobre o ambiente e as condições de trabalho, são analisados os conflitos presentes na interação entre as diversas categorias profissionais. Observou-se que alguns padrões de conflito expressam a distribuição de poder e prestígio que é típica das organizações hospitalares. Nota-se ainda que a interpretação que os funcionários fazem acerca das suas experiências no interior da organização é mediada por representações sociais mais abrangentes, engendradas pelo contexto social mais amplo no qual a organização se insere.

Palavras-chave Recursos Humanos em Saúde; Instituições de Saúde; Organizações; Pessoal de Saúde 


\section{Introdução}

Este artigo discute uma parcela dos dados produzidos pelo projeto Gestão de Qualidade e Cultura em Organizações Públicas de Saúde, desenvolvido no Centro de Pesquisas Hospital Evandro Chagas (CPqHEC), Fundação Oswaldo Cruz (FIOCRUZ). A pesquisa procurou identificar as percepções e opiniões dos membros da organização acerca do ambiente e das relações de trabalho no CPqHEC.

Os dados apresentados privilegiam questões relacionadas ao campo da gestão dos recursos humanos, focalizando-se questões relativas ao treinamento e desenvolvimento e, principalmente, à interação muitas vezes conflituosa entre os diferentes grupos funcionais no interior da organização. Essas tensões ou conflitos refletem, em alguma medida, a dissonância parcial entre os objetivos organizacionais e os interesses dos grupos e indivíduos que dela fazem parte.

Como amplamente discutido na literatura sociológica, nas sociedades contemporâneas, toda organização baseia-se numa estrutura, mais ou menos complexa, de divisão e especialização do trabalho. Trata-se de um requisito funcional, sem o qual uma organização complexa não conseguiria alcançar seus objetivos. A divisão do trabalho implica a articulação entre indivíduos e grupos, a fim de atender aos objetivos da organização. Embora funcionalmente esses grupos devam responder às necessidades operativas da organização, eles tendem a desenvolver interesses específicos, os quais podem dificultar em grau variado a realização dos objetivos organizacionais. Não apenas a forma de desempenho dos papéis sofre essa influência, como os próprios papéis que os sujeitos desempenham internamente também são produzidos externamente, como ocorre com os grupos profissionais típicos, que possuem uma identidade própria e habitus profissionais (conjunto de disposições internalizadas que constituem um substrato para a ação social), formados anteriormente à sua entrada na organização, os quais atualizam-se em seu interior (Bourdieu, 1992).

Procurou-se destacar nesse artigo algumas questões que evidenciam dilemas estruturais na dinâmica de interação dos grupos nas organizações de saúde, mais especificamente nas de tipo hospitalar. Focalizam-se aspectos que tendem a revelar parte do substrato sociológico no qual se funda a cultura dessas organizações, dando visibilidade a uma série de tensões que devem ser consideradas na implementação de inovações orientadas para a melhoria da qualidade nos serviços de saúde.
A análise dos dados busca compreender a relação entre certas particularidades dos diversos grupos que integram a organização e as diferentes visões que se atualizam no cotidiano organizacional. Com base em testes estatísticos, foi possível verificar a relação entre a posição dos indivíduos na estrutura organizacional e suas opiniões e percepções acerca dos processos e relações trabalho.

O conjunto das informações produzidas atende a um duplo objetivo: por um lado constitui um instrumento para subsidiar o planejamento e a tomada de decisões pelos gestores da organização e, por outro, forma uma base empírica que agrega dados para a reflexão sobre organizações públicas de saúde no Brasil. Embora os dados se limitem à pesquisa realizada no CPqHEC, há razões teóricas para supor que os resultados evidenciam algumas características presentes nas organizações hospitalares de um modo geral.

\section{Metodologia}

Para situar minimamente o leitor em relação à organização segundo a qual o estudo foi realizado, segue-se uma sucinta descrição de algumas das suas características principais.

O CPqHEC é um hospital de referência estadual em doenças infecciosas e suas atividades envolvem de forma integrada três campos distintos de atuação: pesquisa, assistência e ensino. Apesar de seu importante trabalho na área assistencial, é o campo da pesquisa, em particular o desenvolvimento de pesquisas clínicas, que caracteriza o foco central das atividades organizacionais. As atividades de ensino abrangem a oferta de cursos de pós-graduação lato sensu nas modalidades de especialização, aperfeiçoamento e atualização, assim como o curso de Residência Médica em Doenças Infecciosas. Contudo, são os programas de pesquisa que constituem o núcleo das atividades do hospital, e é a partir deles que se organizam as atividades de assistência e ensino. O hospital possui também uma forte estrutura laboratorial, igualmente envolvida com os três campos de atuação mencionados. Quanto à organização da demanda, é importante destacar que o atendimento realizado no CPqHEC é necessariamente referenciado por outros serviços ou individualmente por profissionais de saúde. O hospital conta com aproximadamente 230 funcionários, oferece atendimento ambulatorial diário em dois turnos, hospital-dia com capacidade para 16 pacientes e tem em funcionamento 25 leitos para internação. 
O universo da pesquisa foi constituído pelo total de servidores, bolsistas, terceirizados e prestadores autônomos, das áreas-fim e meio, com exceção dos funcionários terceirizados das áreas de limpeza e vigilância. Foram aplicados 200 questionários, alcançando-se uma adesão de $88 \%$ do universo considerado, o que constitui uma proporção bastante elevada, considerando-se o caráter voluntário da participação. Os respondentes foram classificados em cinco categorias profissionais: (a) médicos e pesquisadores; (b) outros profissionais de saúde de nível superior; (c) outros profissionais de nível superior; (d) técnicos e auxiliares de saúde; (e) outros técnicos e auxiliares. Quanto ao vínculo de trabalho, foram classificados em três tipos: (a) servidores públicos; (b) bolsistas; (c) outros (terceirizados e prestadores autônomos). Detectou-se menor grau de adesão por parte do grupo médicos e pesquisadores, mas, ainda assim, 75\% dos indivíduos desse grupo responderam ao questionário.

Com base nas características específicas do CPqHEC anteriormente descritas, decidiu-se, para fins de análise, agregar os médicos e pesquisadores na mesma categoria profissional. Isso porque os médicos, independente de estarem enquadrados no cargo de pesquisador, exercem esta função, na medida em que se encontram todos engajados em projetos de pesquisa. A centralidade das atividades de pesquisa no interior da organização justifica também a inclusão dos pesquisadores não-médicos (biólogos, farmacêuticos etc.) nesse mesmo grupo. Estes últimos são quantitativamente minoritários, correspondendo a aproximadamente um quinto dos indivíduos do grupo.

Na maior parte do questionário, utilizaramse escalas ordinais com quatro opções de resposta, duas das quais remetem a uma avaliação positiva e as outras duas, a uma avaliação negativa, evitando-se assim a tendência a que o respondente optasse por respostas "neutras". Na codificação do banco de dados, foram atribuídos valores numéricos a essas escalas, sem o que seria impossível realizar os testes de correlação. Às escalas, que constituem as opções de resposta nas tabelas apresentadas, foram atribuídos os valores $4,3,2$, e 1, seguindo a ordem das colunas da esquerda para a direita.

Os formulários eram anônimos, como forma de garantir a livre expressão de opiniões pelos respondentes, sem o risco de eventuais constrangimentos ante a administração ou os companheiros de trabalho e, pelas mesmas razões, não houve identificação dos setores. Essa estratégia também contribuiu para que fosse alcançado o elevado percentual de adesão por parte dos funcionários. Deve-se ressaltar que, dado o anonimato dos questionários, a classificação dos respondentes nas categorias profissionais e tipos de vínculo (Tabela 1) baseia-se estritamente no que foi declarado pelos mesmos, contudo não foram detectadas distorções observáveis em relação às informações administrativas oficiais.

\section{Os resultados da pesquisa}

De uma forma geral os resultados da pesquisa apontam para uma avaliação bastante positiva da organização por parte de seus funcionários, como demonstram as respostas obtidas para as três perguntas mencionadas na Figura 1. Observa-se um alto grau de aprovação em relação à administração e ao funcionamento do CPqHEC e, igualmente, uma situação muito positiva quanto à satisfação dos funcionários em trabalhar na organização.

Entretanto, a despeito da ótima avaliação para os quesitos mais genéricos e abrangentes, é possível vislumbrar a existência de problemas pontuais para questões mais específicas. O intuito dessa análise é destacar estas últimas questões - especialmente aquelas que, de alguma forma, ligam-se ao campo da gestão de $\mathrm{RH}$ (Recursos Humanos) - com o objetivo de aprofundar a compreensão de determinados problemas que afetam o cotidiano organizacional. Embora os dados se limitem à pesquisa realizada no CPqHEC, os resultados provavelmente sinalizam algumas características que tendem a se fazer presentes nas organizações hospita-

Tabela 1

Distribuição de funcionários do Centro de Pesquisas do Hospital Evandro Chagas, segundo a categoria profissional e o tipo de vínculo.

\begin{tabular}{|c|c|c|c|c|}
\hline \multirow{2}{*}{ Categoria profissional } & \multicolumn{4}{|c|}{ Tipo de vínculo } \\
\hline & $\begin{array}{l}\text { Servidor } \\
\text { público }\end{array}$ & Bolsista & Outros & Total \\
\hline Médicos e pesquisadores & 31 & 6 & - & 37 \\
\hline $\begin{array}{l}\text { Outros profissionais } \\
\text { de saúde de nível superior }\end{array}$ & 17 & 10 & 4 & 31 \\
\hline $\begin{array}{l}\text { Outros profissionais } \\
\text { de nível superior }\end{array}$ & 11 & 5 & 5 & 21 \\
\hline $\begin{array}{l}\text { Técnicos e auxiliares } \\
\text { de saúde }\end{array}$ & 51 & 19 & 12 & 82 \\
\hline Outros técnicos e auxiliares & 14 & 5 & 10 & 29 \\
\hline Total & 124 & 45 & 31 & 200 \\
\hline
\end{tabular}

Fonte: Pesquisa Gestão de Qualidade e Cultura em Organizações Públicas de Saúde. Escola Nacional Saúde Pública, Fundação Oswaldo Cruz, 2000. 


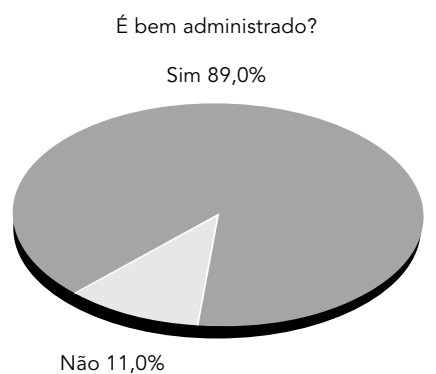

Em sua opinião, o CPqHEC...

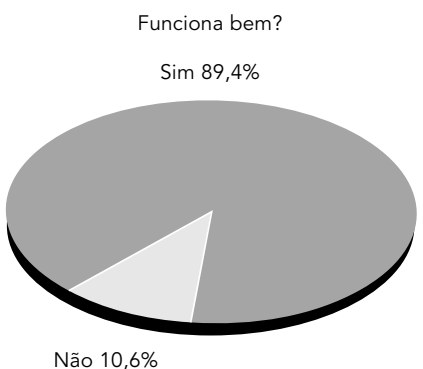

É um lugar onde você se sente satisfeito em trabalhar?

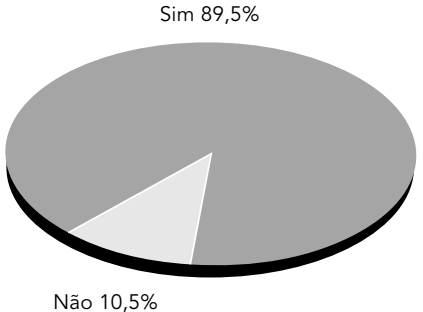

lares de um modo geral e, particularmente, nas de natureza estatal.

\section{Desenvolvimento de recursos humanos}

A discussão sobre o aumento da eficiência e qualidade dos serviços públicos de saúde aponta para uma variedade de ações técnicas e políticas orientadas à instauração de um modelo de gestão pós-burocrática, tanto no âmbito dos sistemas, quanto nas organizações. Foge aos objetivos deste artigo elencar o conjunto de propostas formuladas nessa direção. Todavia, deve-se destacar que, de forma direta ou tangencial, a preocupação com os problemas relativos à gestão de RH está presente, se não em todas, na maior parte dessas propostas.

Sob a ótica das propostas que vêm se aglutinando em torno da idéia de gestão de qualidade, o aprimoramento dos processos de produção exige um esforço permanente de qualificação da força de trabalho. Segundo essas propostas, o constante aprimoramento da competência técnica e o desenvolvimento de habilidades individuais voltadas para o trabalho em grupo e a satisfação do cliente interno e externo colocam-se como requisitos fundamentais para o perfil de RH (Nogueira, 1994). Nesse sentido, tornou-se comum hoje a concepção de que as organizações devem preparar-se para integrar seus trabalhadores a essa nova realidade, alçando conseqüentemente as atividades de desenvolvimento de $\mathrm{RH}$ ao escopo das suas necessidades funcionais.

Levando-se ainda em consideração que tais oportunidades cumprem também um papel motivacional, na medida em que constituem incentivos não econômicos aos trabalhadores, procurou-se apreender a percepção dos funcionários do CPqHEC sobre as oportunidades de treinamento que lhes são oferecidas. A tabela a seguir apresenta as respostas a uma pergunta referente à freqüência com que são oferecidos cursos de capacitação aos funcionários.

Observa-se que $51,3 \%$ dos funcionários afirmam que a oferta de cursos de capacitação e treinamento é algo que ocorre raramente ou nunca. Quando as respostas são analisadas levando-se em consideração o tipo de vínculo dos funcionários, nota-se que, entre aqueles vinculados ao CPqHEC como prestadores autônomos ou trabalhadores terceirizados (tipo de vínculo “outros"), esse percentual chega a $69 \%$, ao passo que, entre os servidores públicos, o percentual é significativamente menor, 47,1\%. Embora esses números reflitam a percepção dos funcionários e não a mensuração objetiva das oportunidades oferecidas, eles apontam para um problema concreto vivido pelas organizações.

As formas "flexíveis" de contratação da força de trabalho têm como conseqüência o estabelecimento de vínculos mais fluidos entre o trabalhador e a organização. Acentua-se o caráter transitório da relação de trabalho, o que, especialmente nas organizações públicas, contrasta com o caráter estável que distingue o vínculo de servidor que continua a vigorar para a outra parte dos trabalhadores. O convívio dessas diferentes formas de contrato gera tensões, latentes ou manifestas, produzindo, não raro, uma hierarquia entre os "estáveis" e os "contratados".

A diversificação das regras e dos mecanismos de pressão e controle vis-a-vis aos diferentes trabalhadores e a conseqüente percepção 
das desigualdades que se produzem são fatores inibidores à produção de um ambiente organizacional que enfatize a cooperação, integração e participação, elementos valorizados pelas mais atuais concepções de gestão. A "precarização" ou "flexibilização" dos vínculos de trabalho colocam, ainda, problemas derivados do cálculo custo/benefício envolvido no investimento em capacitação dos profissionais cuja permanência na organização é incerta ou manifestamente transitória.

Em outra pergunta, pediu-se que o respondente avaliasse as oportunidades de treinamento e desenvolvimento oferecidas por seu setor que tivessem como objetivo a melhoria de seu desempenho profissional. No entanto, no enunciado da pergunta não foi mencionada a palavra "curso", para que, assim, pudesse ser considerada toda e qualquer estratégia de treinamento e qualificação da mão-de-obra posta em prática pela organização.

Quando se deixou vaga a forma de concretização das oportunidades de treinamento e desenvolvimento, observou-se uma considerável melhoria na percepção dos funcionários, caindo para $32,7 \%$ a proporção daqueles que consideraram insuficientes ou inexistentes tais oportunidades. Contudo, manteve-se uma diferença significativa entre as opiniões manifestadas pelos três grupos definidos pelo tipo de vínculo. Isoladamente, esses grupos apresentaram os seguintes percentuais de respostas negativas (oportunidades insuficientes/inexistentes) à pergunta: (a) servidor público, 25,6\%; (b) bolsistas, 40,9\%; c) outros vínculos, 48,4\%. Vale lembrar que, juntos, os dois últimos grupos reúnem aproximadamente dois quintos da força de trabalho no CPqHEC, e que o grande volume de trabalhadores com vínculo precário nesse hospital reflete o quadro geral dos vínculos trabalhistas vigentes na FIOCRUZ. Segundo um relatório de avaliação da instituição, em 1999 apenas $44 \%$ dos trabalhadores da FIOCRUZ eram servidores sob o regime jurídico único (RJU) (Hamilton \& Brito, 1999).

Além de lidar com os problemas derivados da diversificação dos tipos de vínculo trabalhista - fato cada vez mais comum nas organizações públicas -, a gestão dos recursos humanos precisa paralelamente equacionar questões relativas às demandas, necessidades e expectativas das diversas categorias profissionais e/ou grupos funcionais que integram a organização.

As organizações hospitalares enquadramse entre aquelas classificadas como organizações de profissionais (Dussault, 1992) ou de especialistas (Etzione, 1976). Sua característica central é o papel exercido pelos profissio- nais - detentores de um saber especializado na execução dos objetivos da organização. Por essa razão, ocupam o ápice da pirâmide de estratificação interna, constituindo uma fonte de autoridade que se sobrepõe à autoridade administrativa. No CPqHEC, vale lembrar, esse grupo corresponde não apenas aos médicos, mas engloba também os pesquisadores não médicos.

Além do grupo de especialistas, podem-se identificar outros grupos e subgrupos da organização segundo seu pertencimento ou não à área de saúde, o que, por sua vez, determina sua inserção nas atividades fim ou meio. Outro fator de segmentação a ser tomado em consideração é o nível de escolaridade, o que levou a considerarem-se os profissionais de nível superior separadamente dos demais profissionais, tanto na área-fim, quanto na área-meio. Diferentemente da segmentação produzida pelos diferentes tipos de vínculo, a que é derivada das categorias profissionais ou grupos funcionais tende a ser similar no conjunto das organizações hospitalares, onde se observa uma estrutura de grupos semelhante àquela encontrada no CPqHEC.

O pertencimento a uma categoria profissional constitui fator relevante na compreensão das respostas dos funcionários. Quanto à avaliação das oportunidades de treinamento e desenvolvimento em seu setor de trabalho, a heterogeneidade das respostas de diferentes categorias profissionais pode ser explicada conjugando-se dois fatores principais: (a) a posição do grupo no interior da organização; (b) as características associadas às profissões e ocupações.

A pergunta relativa às oportunidades de treinamento (Tabela 4) obtém as melhores avaliações no grupo dos Médicos e Pesquisadores, alcançando entre estes $75,7 \%$ de respostas “ideal" ou "suficiente", ao passo que nos grupos Outros Profissionais de Saúde de Nível Superior e Outros Profissionais de Nivel Superior alcançam respectivamente $51,6 \%$ e $30 \%$. Os médicos e pesquisadores constituem, como já foi mencionado, o grupo central, o núcleo em torno do qual orbitam as demais categorias e, em última instância, aquele que por excelência institui a identidade dessas organizações de especialistas. Do ponto de vista dos objetivos organizacionais, é evidente que a alocação dos recursos, entendidos em sentido amplo, tenda a priorizar o investimento nessa categoria. Todavia, isso produz um certo grau de conflito com outras categorias profissionais que não têm seus interesses e expectativas contemplados na mesma medida. 
Tabela 2

Freqüência com que são oferecidos cursos de captação e treinamento no setor de trabalho.

\begin{tabular}{lcccc}
\hline $\begin{array}{l}\text { (n= 193) } \\
\text { Tipo de Vínculo }\end{array}$ & $\begin{array}{c}\text { Sempre } \\
(\%)\end{array}$ & $\begin{array}{c}\text { Opções de resposta } \\
\text { Muitas vezes } \\
(\%)\end{array}$ & $\begin{array}{c}\text { Raramente } \\
(\%)\end{array}$ & $\begin{array}{c}\text { Nunca } \\
(\%)\end{array}$ \\
\hline Servidor público & 21,5 & 31,4 & 40,5 & 6,6 \\
Bolsista & 20,9 & 27,9 & 37,2 & 14,0 \\
Outros vínculos & 17,2 & 13,8 & 27,6 & 41,4 \\
Total & 20,7 & 28,0 & 37,8 & 13,5 \\
\hline
\end{tabular}

Fonte: Pesquisa Gestão de Qualidade e Cultura em Organizações Públicas de Saúde. Escola Nacional de Saúde Pública, Fundação Oswaldo Cruz, 2000. Nota: $\mathrm{p}$-valor $=0,000$

Tabela 3

Em seu setor de trabalho, as oportunidades de treinamento

e desenvolvimento para melhorar o desempenho profissional são?

\begin{tabular}{lcccc}
\hline $\begin{array}{l}\text { (n= 196) } \\
\text { Tipo de vínculo }\end{array}$ & $\begin{array}{c}\text { Opções de resposta } \\
\text { Ideal }\end{array}$ & $\begin{array}{c}\text { Suficiente } \\
(\%)\end{array}$ & $\begin{array}{c}\text { Insuficiente } \\
(\%)\end{array}$ & $\begin{array}{c}\text { Não houve } \\
(\%)\end{array}$ \\
\hline Servidor público & 40,5 & 33,9 & 20,7 & 5,0 \\
Bolsista & 40,9 & 18,2 & 36,4 & 4,5 \\
Outros vínculos & 38,7 & 12,9 & 25,8 & 22,6 \\
Total & 40,3 & 27,0 & 25,0 & 7,7 \\
\hline
\end{tabular}

Fonte: Pesquisa Gestão de Qualidade e Cultura em Organizações Públicas de Saúde. Escola Nacional de Saúde Pública, Fundação Oswaldo Cruz, 2000. Nota: $\mathrm{p}$-valor $=0,003$

Tabela 4

Oportunidades no setor para treinamento e desenvolvimento que favoreçam o desempenho de novas funções.

\begin{tabular}{|c|c|c|c|c|}
\hline \multirow{2}{*}{$\begin{array}{l}(\mathbf{n}=191) \\
\text { Categoria profissional }\end{array}$} & \multicolumn{4}{|c|}{ Opções de resposta } \\
\hline & $\begin{array}{l}\text { Ideal } \\
(\%)\end{array}$ & $\begin{array}{c}\text { Suficiente } \\
(\%)\end{array}$ & $\begin{array}{c}\text { Insuficiente } \\
(\%)\end{array}$ & $\begin{array}{c}\text { Não houve } \\
(\%)\end{array}$ \\
\hline Médicos e pesquisadores & 51,4 & 24,3 & 18,9 & 5,4 \\
\hline $\begin{array}{l}\text { Outros profissionais } \\
\text { de saúde nível superior }\end{array}$ & 25,8 & 25,8 & 48,4 & - \\
\hline $\begin{array}{l}\text { Outros profissionais } \\
\text { de nível superior }\end{array}$ & 20,0 & 10,0 & 45,0 & 25,0 \\
\hline Técnico/auxiliar de saúde & 22,1 & 32,5 & 31,2 & 14,3 \\
\hline Outros técnicos/auxiliares & 23,1 & 46,2 & 15,4 & 15,4 \\
\hline Total & 28,3 & 29,3 & 30,9 & 11,5 \\
\hline
\end{tabular}

Fonte: Pesquisa Gestão de Qualidade e Cultura em Organizações Públicas de Saúde. Escola Nacional de Saúde Pública, Fundação Oswaldo Cruz, 2000. Nota: $p$-valor $=0,002$
Os demais profissionais de saúde de nível superior, se, por um lado, beneficiam-se por também pertencerem à área-fim, por outro, não escapam dos efeitos derivados da hierarquia de poder e prestígio das profissões de saúde. Sua percepção em relação às oportunidades oferecidas pela organização encontra-se num ponto intermediário entre as manifestadas pelos médicos e pesquisadores e aquelas expressadas pelos profissionais de nível superior pertencentes à área-meio. Este terceiro grupo é o que apresenta as percepções mais negativas quando avalia os quesitos relativos ao desenvolvimento de recursos humanos.

No que se refere aos Técnicos e Auxiliares, as respostas "ideal" ou "suficiente" atingem $52,6 \%$ para os da área-fim e $69,3 \%$ para os da área-meio. Embora seja possível, ou mesmo necessário, que uma organização, em um dado momento, priorize o investimento nesses grupos como forma de homogeneizar os padrões de eficiência e qualidade, não é usual que, ao longo do tempo, eles continuem a desfrutar de prioridade no manejo dos recursos, o que se tornaria contraproducente para a organização. No CPqHEC não havia, na ocasião da pesquisa, tampouco em passado recente, nenhuma orientação que focalizasse prioritariamente a qualificação dos técnicos e auxiliares; logo, a análise dos dados não pode ser feita por essa perspectiva de interpretação. A existência dessa proporção de percepções positivas nos grupos funcionais hierarquicamente inferiores não pode, assim, ser explicada por eventos particulares da organização estudada.

O fato de os técnicos e auxiliares da áreameio estarem consideravelmente mais satisfeitos com as oportunidades que lhes são oferecidas do que os Outros Profissionais de Saúde de Nível Superior (área-fim) e Outros Profissionais de Nível Superior (área-meio) pode ser compreendido por meio da perspectiva de carreira que informa os diferentes grupos. A idéia de carreira profissional como um elemento de autodesenvolvimento, não apenas econômico, mas também social, tende a integrar mais fortemente o ethos das profissões que requerem maior grau de instrução/qualificação. Trabalhar em uma empresa ou instituição de prestígio, ocupar um cargo tido como de maior responsabilidade e aprimorar-se para ocupar progressivamente posições mais importantes são pontos que fazem parte das aspirações e projetos desses profissionais. Além do ganho econômico, há a valorização dos aspectos simbólicos que projetam os indivíduos para cima na hierarquia de status, seja em seu círculo profissional, seja no espaço mais amplo das suas rela- 
ções sociais. Como mostram outros estudos sobre camadas médias urbanas, a noção de projeto direciona as estratégias de realização pessoal - que se torna também ascensão social de muitos indivíduos desse segmento (Vaitsman, 1994; Velho, 1999).

Por essa mesma abordagem pode-se compreender a relativa acomodação dos grupos inferiores, comparativamente aos profissionais de nível superior que não são "médicos e pesquisadores", alvo das prioridades organizacionais. A restrição relativa de oportunidades para estes, comparativamente ao grupo priorizado, entra em conflito com suas aspirações e expectativas. Para os profissionais de nível superior que não pertencem à área de saúde, a situação é ainda mais crítica, pois, embora sejam igualmente afetados pelas aspirações derivadas da noção de carreira, ocupam uma posição ainda mais periférica na organização. Dado o caráter específico das organizações de saúde, é coerente que o investimento no treinamento e desenvolvimento desses profissionais seja, em circunstâncias normais, menos priorizado que o investimento nos profissionais de saúde. Isso significa que, mesmo que sejam tomadas medidas que focalizem excepcionalmente esse grupo, o conflito entre seus objetivos e os da organização se manterá latente, pois suas possibilidades de desenvolvimento são estruturalmente limitadas pela natureza das organizações de saúde.

Por outro lado, do ponto de vista da proposta de uma administração pública gerencial e de uma gestão voltada para a qualidade, os trabalhadores das áreas-meio desempenham um papel igualmente crucial na organização, já que são eles que operam a engrenagem do sistema, viabilizando o fluxo de vários tipos de processos. Seu modo de trabalhar pode fazer andar ou emperrar a máquina. Nesse sentido, tem-se destacado a necessidade de maior atenção para com esses grupos de trabalhadores. Entretanto, o maior investimento e o fortalecimento da área-meio induzem o acirramento da tensão na sua relação com os especialistas, situados na área-fim.

A gestão orientada para a qualidade enfatiza necessidade de se produzir um ambiente de cooperação e participação, no qual os trabalhadores envolvam-se na consecução dos objetivos organizacionais, desfrutem de maior autonomia no âmbito de suas funções e, enfim, conjuguem realização pessoal e trabalho. Segundo essa visão, a satisfação do trabalhador provoca efeitos positivos sobre a qualidade e produtividade do trabalho, devendo, portanto, constituir interesse da própria organização.
Produzir tal ambiente e assegurar um certo grau de satisfação entre os trabalhadores é uma operação que se realiza mediante variadas ações, mais ou menos difusas, porém articuladas. A orientação de sentido e a coordenação dessas ações situam-se, certamente, na dimensão da gestão de RH, ainda que a operacionalização das mesmas extrapole os limites destes departamentos.

No setor público, a autonomia das organizações na gestão de RH é parcialmente limitada, pois grande partes das normas de contratação e demissão originam-se externamente e impõem-se de forma rígida e indiferenciada. $\mathrm{O}$ mesmo problema afeta a definição dos planos de carreira e das políticas de benefícios e incentivos. Dussault (1992) chama a atenção para o fato de que as organizações públicas têm seu quadro de funcionamento regulado externamente e que objetivos contrários aos seus podem ser impostos pelas autoridades externas. "Em outras palavras, as organizações de serviços públicos são mais vulneráveis à interferência política, no sentido geral do termo" (Dussault, 1992:13).

No Brasil, o processo de reforma do Estado iniciado na década de 90 tem tentado promover maior flexibilidade na administração pública mediante a implementação de um modelo gerencial em substituição ao tradicional modelo burocrático. O ideário da reforma abre a perspectiva de maior autonomia gerencial para as organizações públicas, que passariam a ser controladas por seus resultados, em vez do rígido controle sobre os processos. Costa et al. (2000), em um estudo sobre mudanças organizacionais em hospitais públicos das regiões metropolitanas do Rio de Janeiro e São Paulo, afirmam que "no setor saúde assiste-se a uma reforma silenciosa e não explícita" (Costa et al., 2000:439), por meio de um conjunto heterogêneo de ações e estratégias e um alto grau de experimentalismo. Identificam a gestão de recursos humanos como um dos campos que vêm sendo alvo de inovações organizacionais orientadas para a busca de maior autonomia e ressaltam a flexibilização contratual e os incentivos ao desempenho como estratégias colocadas em prática pelos hospitais pesquisados. Isso, de certo modo, aponta para a construção de um consenso acerca da necessidade de novas formas de gestão dos recursos humanos como um dos meios para se alcançar maior eficiência e qualidade nos serviços públicos de saúde.

No entanto, como aponta a própria pesquisa mencionada, as ações praticadas nesse campo têm se direcionado para a flexibilização dos vínculos trabalhistas, de forma a imprimir 
maior plasticidade à gestão de RH. Livrando-se das normas do RJU, essas organizações buscam diminuir e racionalizar os gastos e, também, viabilizar políticas de incremento salarial seletivo.

Pensar a gestão de RH em um sentido que contemple a produção de um ambiente organizacional orientado para a satisfação dos funcionários vai além da implementação de uma política seletiva de incentivos monetários. As condições e situações que geram nos funcionários sensações de injustiça, opressão ou insatisfação não se restringem aos aspectos de ordem econômica/salarial. Embora a remuneração seja um fator importante, do ponto de vista teórico, é insuficiente, e em muitas situações até mesmo inadequado, para se compreenderem alguns dos problemas que afetam a motivação dos trabalhadores

\section{Conflito entre categorias profissionais}

As organizações hospitalares constituem espaços sociais heterogêneos nos quais interagem diferentes grupos e papéis. Possuem uma dinâmica interna que, no cotidiano, atualiza identidades, hierarquias, conflitos e alianças. Embora o grupo formado pelos médicos materialize a própria identidade da organização, do ponto de vista quantitativo representa uma parcela relativamente pequena dos trabalhadores (no CPqHEC, os médicos e pesquisadores somam cerca de $20 \%$ dos funcionários). Esse grupo principal interage com os outros grupos que dão suporte à realização de suas atividades. A relação dos médicos e pesquisadores com os outros grupos é suscetível às tensões de legitimação, na medida em que o exercício de seu poder e autoridade causa ingerência ou pressão sobre o trabalho das demais categorias, "invadindo" áreas de competência que essas últimas consideram de sua responsabilidade. Os conflitos e as tensões são inerentes às organizações e, em última instância, alimentam-se das tentativas para conservar ou alterar a distribuição do poder.

Em uma das perguntas do questionário, foi pedido que se opinasse sobre a freqüência com que as relações profissionais no CPqHEC têm por base a hierarquia e o controle. As respostas a essa pergunta, apresentadas na Tabela 5, apontam para o grau de autonomia dos médicos e pesquisadores no interior da organização e, simultaneamente, dá indicações do poder que exercem sobre as demais categorias. Enquanto nesse grupo 41,9\% dos respondentes afirmaram que no CPqHEC as relações entre profissionais, "sempre" ou "muitas vezes", têm por base a hierarquia e o controle, entre os $\mathrm{Ou}$ tros Profissionais de Saúde de Nível Superior e os Técnicos e Auxiliares de Saúde esse percentual alcança, respectivamente, 65,3\% e 81,9\%. Essas duas categorias profissionais, mais que as da área-meio, encontram-se sob forte tutela dos médicos, os quais desfrutam da posição dominante na hierarquia das profissões/ocupações em saúde.

Como já amplamente discutido pela Sociologia das Profissões (Freidson, 1998), a autonomia dos médicos baseia-se no monopólio legítimo de um tipo de conhecimento específico que caracteriza seu campo de trabalho. Em razão disso, nenhum outro grupo da organização pode legitimamente exercer controle ou ingerência sobre sua atuação profissional. Mesmo entre os pares, a possibilidade de controle ou interferência é bastante limitada, uma vez que a autonomia na condução dos casos é resguardada pelos preceitos éticos, corporativos e culturais, próprios da profissão. É compreensível, então, que os médicos - e, igualmente, os pesquisadores - percebam menos que outros grupos da organização a ação das hierarquias e controles no ambiente de trabalho.

Em relação aos Outros Profissionais de Saúde de Nível Superior - enfermeiros, majoritariamente, mas também nutricionistas, psicólogos, assistentes sociais etc -, nota-se a dificuldade de afirmação de um campo de autonomia no interior das organizações de saúde, o que aponta para as tensões inerentes à prática do atendimento multiprofissional como uma das estratégias da atenção à saúde. A inexistência de relações mais igualitárias entre esses profissionais e os médicos no que se refere à autonomia e à distribuição do poder constitui a regra para as organizações hospitalares.

Os Técnicos e Auxiliares de Saúde formam o grupo sobre o qual a sobreposição das diferentes fontes de poder e autoridade, e das hierarquias que elas estabelecem, fazem-se sentir com maior força. Correspondem às funções subordinadas da estrutura organizacional e, não possuindo a autonomia característica das profissões, encontram-se mais sujeitos à ação da autoridade administrativa. Por outro lado, tratando-se de ocupações com menor grau de qualificação, mas diretamente vinculadas ao espaço no qual a relação entre saber e poder é explícita, é sobre esses funcionários que mais recai a permanente pressão e controle que emana da hierarquia fundada na legitimidade do saber médico, ou seja, na autoridade profissional destes últimos.

As assimetrias de poder nas relações que se estabelecem entre grupos e indivíduos no inte- 
rior das organizações podem desfrutar de maior ou menor legitimidade e, da mesma forma, assentar-se sobre regras formais ou preceitos informais. Vale ressaltar que tanto as regras formais quanto os preceitos informais podem ser reconhecidos como legítimos ou ilegítimos, não sendo o estatuto de formalidade uma garantia para a aceitação consentida da norma; tampouco, o da informalidade é um impedimento à aceitação de determinadas práticas. A legitimidade das assimetrias de poder é um ponto crucial para que não seja deflagrado um clima de conflito e/ou injustiça. A idéia de privilégio emerge no momento em que regras ou práticas instituídas beneficiam grupos ou indivíduos específicos, sem o consentimento e aceitação dos demais integrantes da organização. O que caracteriza o privilégio não é a existência de uma situação marcada pela desigualdade de condições ou oportunidades, mas sim a ausência de atributos que confiram legitimidade a essa dada situação de desigualdade, ou seja, a percepção de privilégio está ligada à percepção de poder ilegítimo e sentimento de injustiça.

Pelos dados levantados, há indicações de que os controles e hierarquias que regulam as relações entre profissionais no CPqHEC gozam de legitimidade para a maior parte dos grupos/segmentos da organização. Embora 66,9\% dos trabalhadores pesquisados tenham afirmado que, sempre ou muitas vezes, as relações entre profissionais têm por base a hierarquia e o controle, e $59,7 \%$ tenham declarado que os privilégios de algumas categorias sempre ou muitas vezes atrapalham o trabalho em equipe (Tabela 6), a correlação estatística (r) entre ambas as questões é bastante fraca, apenas 0,201 (Pvalor $=0,014$ ), ainda que apresente significância estatística. Quando a correlação entre ambas as questões é calculada tomando por base as diferentes categorias profissionais, observase que, de fato, ela só existe para o grupo $\mathrm{Ou}$ tros Técnicos e Auxiliares, no qual alcança o valor $\mathrm{r}=0,457$ (P-valor $=0,029$ ), sendo a correlação observada para o conjunto apenas um reflexo desse grupo particular. Vale destacar também a inexistência de correlação estatística entre a Tabela 5 (hierarquia) e a Tabela 7 (igualdade das regras).

Isso significa que, no conjunto dos funcionários - excetuando-se os técnicos e auxiliares da área-meio -, a percepção de que alguns membros da organização desfrutam de privilégios não implica a deslegitimação das hierarquias internas que estruturam a organização. No entanto, a existência da correlação $r=0,457$ observada no grupo excetuado deve ser inter-

\begin{tabular}{|c|c|c|c|c|}
\hline \multicolumn{5}{|c|}{$\begin{array}{l}\text { Freqüência com que as relações entre os profissionais } \\
\text { têm por base a hierarquia e o controle. }\end{array}$} \\
\hline \multirow{2}{*}{$\begin{array}{l}(n=163) \\
\text { Categoria profissional }\end{array}$} & \multicolumn{4}{|c|}{ Opções de resposta } \\
\hline & $\begin{array}{l}\text { Sempre } \\
(\%)\end{array}$ & $\begin{array}{l}\text { Muitas vezes } \\
(\%)\end{array}$ & $\begin{array}{l}\text { Raramente } \\
\qquad \%)\end{array}$ & $\begin{array}{c}\text { Nunca } \\
(\%)\end{array}$ \\
\hline Médicos e pesquisadores & 3,2 & 38,7 & 51,6 & 6,5 \\
\hline $\begin{array}{l}\text { Outros profissionais } \\
\text { de saúde nível superior }\end{array}$ & 17,2 & 48,3 & 31,0 & 3,4 \\
\hline $\begin{array}{l}\text { Outros profissionais } \\
\text { de nível superior }\end{array}$ & 21,1 & 47,4 & 26,3 & 5,3 \\
\hline Técnico/auxiliar de saúde & 31,1 & 50,8 & 14,8 & 3,3 \\
\hline Outros técnicos/auxiliares & 21,7 & 39,1 & 26,1 & 13,0 \\
\hline Total & 20,9 & 46,0 & 27,6 & 5,5 \\
\hline
\end{tabular}

Fonte: Pesquisa Gestão de Qualidade e Cultura em Organizações Públicas de Saúde. Escola Nacional de Saúde Pública, Fundação Oswaldo Cruz, 2000 Notas: $p$-valor $=0,014$.

Para a execução do teste, as colunas "raramente" e "nunca" foram agregadas para que o número de células com freqüência esperada < 5 não ultrapassasse $20 \%$. Considerando o peso de cada categoria, a ausência de respostas foi proporcionalmente maior nos grupos Técnicos e Auxiliares de Saúde (21 missing) e Outros Técnicos e Auxiliares (6 missing).

Tabela 6

Freqüência com que os privilégios de algumas categorias atrapalham o trabalho em equipe.

\begin{tabular}{lcccc}
\hline $\begin{array}{l}\text { (n=169) } \\
\text { Categoria profissional }\end{array}$ & $\begin{array}{c}\text { Sempre } \\
(\%)\end{array}$ & $\begin{array}{c}\text { Opções de resposta } \\
\text { Muitas vezes } \\
(\%)\end{array}$ & $\begin{array}{c}\text { Raramente } \\
(\%)\end{array}$ & $\begin{array}{c}\text { Nunca } \\
(\%)\end{array}$ \\
\hline $\begin{array}{l}\text { Médicos e pesquisadores } \\
\begin{array}{l}\text { Outros profissionais } \\
\text { de saúde nível superior }\end{array}\end{array}$ & 18,8 & 18,8 & 53,1 & 9,4 \\
$\begin{array}{l}\text { Outros profissionais } \\
\text { de nível superior }\end{array}$ & 25,0 & 42,9 & 21,4 & 10,7 \\
$\begin{array}{l}\text { Técnico/auxiliar de saúde } \\
\text { Outros técnicos/auxiliares }\end{array}$ & 29,0 & 55,0 & 10,0 & 15,0 \\
Total & 40,7 & 32,3 & 21,0 & 17,7 \\
\hline
\end{tabular}

Fonte: Pesquisa Gestão de Qualidade e Cultura em Organizações Públicas de Saúde. Escola Nacional de Saúde Pública, Fundação Oswaldo Cruz, 2000. Notas: $p$-valor $=0,026$

Considerando o peso de cada categoria, a ausência de respostas foi proporcionalmente maior nos grupos Técnicos e Auxiliares de Saúde (20 missing) e Médicos e Pesquisadores (5 missing).

pretada como uma indicação de que nesse grupo específico as hierarquias em questão encontram maior dificuldade para se legitimarem.

Os técnicos e auxiliares da área-meio integram os escalões inferiores da organização e encontram-se em posições mais subordinadas à estrutura hierárquica fundada na autoridade administrativa. Por outro lado, por estarem na 
Tabela 7

Freqüência com que as regras são iguais para todos,

independente da categoria profissional.

\begin{tabular}{|c|c|c|c|c|}
\hline \multirow{2}{*}{$\begin{array}{l}(n=168) \\
\text { Categoria Profissional }\end{array}$} & \multicolumn{4}{|c|}{ Opções de resposta } \\
\hline & $\begin{array}{l}\text { Sempre } \\
(\%)\end{array}$ & $\begin{array}{c}\text { Muitas vezes } \\
(\%)\end{array}$ & $\begin{array}{c}\text { Raramente } \\
\text { (\%) }\end{array}$ & $\begin{array}{c}\text { Nunca } \\
(\%)\end{array}$ \\
\hline \multicolumn{5}{|l|}{ Área-fim } \\
\hline Médicos e pesquisadores & 9,4 & 31,3 & 46,9 & 12,5 \\
\hline $\begin{array}{l}\text { Outros profissionais } \\
\text { de saúde nível superior }\end{array}$ & 10,7 & 28,6 & 39,3 & 21,4 \\
\hline Técnico/auxiliar de saúde & 21,5 & 27,7 & 35,4 & 15,4 \\
\hline \multicolumn{5}{|l|}{ Área-meio } \\
\hline $\begin{array}{l}\text { Outros profissionais } \\
\text { de nível superior }\end{array}$ & 14,3 & 19,0 & 42,9 & 23,8 \\
\hline Outros técnicos/auxiliares & 9,1 & 18,2 & 13,6 & 59,1 \\
\hline Total & 14,9 & 26,2 & 36,3 & 22,6 \\
\hline
\end{tabular}

Fonte: Pesquisa Gestão de Qualidade e Cultura em Organização,

Escola Nacional de Saúde Pública, Fundação Oswaldo Cruz, 2000.

Notas: $p$-valor $=0,004$

Para a execução do teste, as colunas "sempre" e "muitas vezes" foram agregadas

para que o número de células com freqüência esperada $<5$ não ultrapassasse

$20 \%$. Considerando o peso de cada categoria, a ausência de respostas foi

proporcionalmente maior nos grupos Outros Técnicos e Auxiliares (7 missing)

e Técnicos e Auxiliares de Saúde (17 missing).

área-meio são menos expostos à socialização que tende a legitimar o poder e autoridade fundados na hierarquia de profissões/ocupações de saúde, tal como ocorre com os técnicos e auxiliares da área-fim. A associação entre hierarquias e privilégios, observada nas percepções desse grupo, pode ser compreendida considerando-se a hipótese de que sua posição duplamente periférica na organização, quanto ao grau de escolarização e, principalmente, quanto à área de atuação, dificulta a constituição de uma identidade referida ao trabalho em saúde propriamente dito e, conseqüentemente, a aceitação das formas pelas quais as desigualdades e assimetrias de poder se fazem presentes nas relações entre trabalhadores nas organizações de saúde, especialmente nas hospitalares.

Todavia, como já foi anteriormente mencionado, a percepção de que existem privilégios, isto é, benefícios ilegítimos para alguns grupos ou indivíduos, é, de um modo geral, bastante difundida entre os funcionários do CPqHEC. Esses privilégios podem, em tese, expressar-se através de tolerância e permissividade para com determinadas práticas que se desviam da obediência às normas, ou mesmo pela ausência de legitimidade para alguma norma instituída. Em uma das perguntas, pediu-se a opinião acerca da freqüência com que, na opinião deles, as regras são iguais para to- dos os funcionários, independentemente da categoria profissional (Tabela 7).

A percepção que os funcionários apresentam sobre a igualdade das regras para os diferentes grupos no interior da organização (Tabela 7) revela, através da correlação $r=-0,469$ (P-valor 0,000) que mantém com a Tabela 6 (privilégios), que tais desigualdades, em alguma medida, carecem de legitimidade, especialmente para os indivíduos dos grupos Outros Técnicos e Auxiliares $(\mathrm{r}=0,668$; $\mathrm{p}$-valor $=0,001)$ e Outros Profissionais de Saúde de Nível Superior $(\mathrm{r}=0,680$; $\mathrm{p}$-valor $=0,000)$.

Nota-se ainda que, na tabela anterior, há entre os trabalhadores da área-meio uma tendência a apresentarem percepções mais negativas sobre as relações que se estabelecem no cotidiano organizacional, o que reforça a hipótese de que a posição periférica no interior da organização e a conseqüente dificuldade de vinculação identitária com o campo do trabalho em saúde produz conflitos - latentes ou manifestos - entre estes profissionais e os da área-fim. Esses conflitos podem expressar-se de diversas maneiras, inclusive sob a forma de não legitimação de regras ou práticas instituídas que, supostamente, distribuem desigualmente benefícios, "privilegiando" os trabalhadores da área-fim, particularmente o grupo dos especialistas, que detêm a posição de maior influência e prestígio no interior da organização. Vale lembrar que as tensões derivadas da estrutura de grupos da organização contrapõem os médicos e pesquisadores não exclusivamente aos trabalhadores da área-meio, como também aos demais trabalhadores da área-fim. Tal como na sociedade, observa-se que, no espaço da organização, a estrutura das relações de poder tem efeito estruturante na produção de valores, percepções e práticas dos sujeitos a ela submetidos.

Em maior ou menor grau, o conflito sempre está presente no interior das organizações, sejam elas de qualquer tipo. Como coloca Malik (1998), a inexistência de conflito é incompatível com o conceito de organização. Na caracterização do conflito estariam, como condições antecedentes, a existência de grupos diferenciados, a interdependência de tarefas e o compartilhamento de recursos. No entanto, algumas especificidades caracterizam esse fenômeno nas organizações de saúde, especialmente nas de tipo hospitalar.

A integração dos técnicos e auxiliares da área-meio parece ser um problema particularmente acentuado, uma vez que as avaliações negativas desse grupo tendem a ser recorrentes nas perguntas que objetivam capturar as- 
pectos relativos ao clima organizacional. Quando se perguntou se no CPqHEC os funcionários, independentemente do cargo que ocupam, são tratados com respeito, $50 \%$ dos técnicos e auxiliares da área-meio assinalaram as opções raramente ou nunca, ao passo que, para o conjunto formado pelas demais categorias profissionais, esse percentual alcança apenas 13,3\% (Tabela 8).

As representações que os funcionários têm sobre o reconhecimento - ou a falta dele - do seu esforço e dedicação ao trabalho por parte da organização (Tabela 9) deixam transparecer a oposição entre os especialistas (médicos e pesquisadores) e os demais grupos que orbitam ao seu redor, viabilizando, direta ou indiretamente, a execução das suas atividades, por meio das quais se concretizam os objetivos organizacionais. Nos grupos subordinados, uma parcela expressiva dos trabalhadores considera que sua dedicação não é devidamente reconhecida pela organização. Enquanto $81,3 \%$ dos Médicos e Pesquisadores declararam que quem é comprometido com o trabalho é reconhecido sempre ou muitas vezes, apenas $42,3 \%$ dos técnicos e auxiliares da área-meio afirmaram o mesmo. Este último grupo novamente apresentou as percepções mais negativas, embora ele aqui seja acompanhado pelos demais grupos na contraposição aos médicos e pesquisadores. Observe-se também a correlação r 0,635 (p-valor $=0,000$ ) entre a Tabela 9 (reconhecimento) e a Tabela 10 (avaliação).

Contudo, o sentimento de não reconhecimento, compartilhado por boa parte dos membros dos grupos periféricos, deve ser compreendido, também, a partir da análise de elementos externos à organização. A detecção desse mesmo sentimento em funcionários de outras organizações públicas, da área de saúde ou não, tem levado a se buscar nos elementos constitutivos da sociedade brasileira a compreensão da recorrência desse fato.

Como discutido por Barbosa (1999), valendo-se de pesquisa realizada com funcionários públicos, e por Vaitsman (2001), com base em dados de pesquisa com profissionais de saúde de um hospital municipal do Rio de Janeiro, apesar de prevalecer a opinião de que o mérito e o desempenho devam ser os principais parâmetros para avaliação dos servidores, os funcionários de organizações públicas tendem a acreditar que, na prática, os que possuem algum tipo de "apadrinhamento", ou bom relacionamento com as chefias, acabam sendo mais bem sucedidos. Ainda que aspirações e atitudes universalistas sejam bem abrangentes entre os servidores, a isso não corresponde a
Tabela 8

Os funcionários são tratados com respeito, independente do cargo que ocupam.

\begin{tabular}{lcccc}
\hline $\begin{array}{l}\text { (n=191) } \\
\text { Categoria profissional }\end{array}$ & $\begin{array}{c}\text { Sempre } \\
(\%)\end{array}$ & $\begin{array}{c}\text { Opções de resposta } \\
\text { Muitas vezes } \\
(\%)\end{array}$ & $\begin{array}{c}\text { Raramente } \\
(\%)\end{array}$ & $\begin{array}{c}\text { Nunca } \\
\text { (\%) }\end{array}$ \\
\hline $\begin{array}{l}\text { Médicos e pesquisadores } \\
\begin{array}{l}\text { Outros profissionais } \\
\text { de saúde nível superior }\end{array}\end{array}$ & 29,4 & 61,8 & 8,8 & - \\
$\begin{array}{l}\text { Outros profissionais } \\
\text { de nível superior }\end{array}$ & 30,0 & 63,3 & 6,7 & - \\
$\begin{array}{l}\text { Técnicos/auxiliar de saúde } \\
\text { Outros técnicos/auxiliares }\end{array}$ & 33,3 & 52,4 & 9,5 & 4,8 \\
Total & 26,9 & 45,0 & 16,3 & 1,3 \\
\hline
\end{tabular}

Fonte: Pesquisa Gestão de Qualidade e Cultura em Organizações Públicas de Saúde. Escola Nacional de Saúde Pública, Fundação Oswaldo Cruz, 2000. Notas: $p$-valor $=0,001$.

Para a execução do teste as colunas "raramente" e "nunca" foram agregadas para que o número de células com freqüência esperada < 5 não ultrapassasse $20 \%$.

Tabela 9

Com que freqüência aquele que é comprometido com o trabalho é reconhecido.

\begin{tabular}{lcccc}
\hline $\begin{array}{l}\text { (n= 180) } \\
\text { Categoria profissional }\end{array}$ & $\begin{array}{c}\text { Sempre } \\
(\%)\end{array}$ & $\begin{array}{c}\text { Opções de resposta } \\
\text { Muitas vezes } \\
(\%)\end{array}$ & $\begin{array}{c}\text { Raramente } \\
(\%)\end{array}$ & $\begin{array}{c}\text { Nunca } \\
(\%)\end{array}$ \\
\hline $\begin{array}{l}\text { Médicos e pesquisadores } \\
\text { Outros profissionais }\end{array}$ & 18,8 & 62,5 & 15,6 & 3,1 \\
de saúde nível superior & 13,3 & 46,7 & 40,0 & \\
$\begin{array}{l}\text { Outros profissionais } \\
\text { de nível superior }\end{array}$ & 10,5 & 52,6 & 36,8 & \\
$\begin{array}{l}\text { Técnico/auxiliar de saúde } \\
\text { Outros técnicos/auxiliares }\end{array}$ & 27,4 & 34,2 & 27,4 & 11,0 \\
Total & 19,2 & 23,1 & 50,0 & 7,7 \\
\hline
\end{tabular}

Fonte: Pesquisa Gestão de Qualidade e Cultura em Organizações Públicas de Saúde. Escola Nacional de Saúde Pública, Fundação Oswaldo Cruz, 2000. Notas: $p$-valor $=0,036$

Para a execução do teste, as colunas "raramente" e "nunca" foram agregadas para que o número de células com freqüência esperada < 5 não ultrapassasse $20 \%$. Considerando o peso de cada grupo, as não-respostas (missing) distribuíram-se de forma mais ou menos uniforme entre as diferentes categorias profissionais.

crença de que as regras do jogo sejam as mesmas para todos, o que provavelmente tem implicações negativas do ponto de vista da formação de um ethos de envolvimento e comprometimento com a coisa pública.

O paradoxo entre as características relacionais e hierárquicas (DaMatta, 2000) constitutivas da cultura brasileira e a incorporação dos valores de mérito e igualdade, fundadores dos princípios gerenciais modernos, é uma fonte geradora de contradições permanentes no funcionamento das organizações públicas brasi- 
Tabela 10

Com que freqüência o desempenho dos funcionários é avaliado adequadamente.

\begin{tabular}{lcccc}
\hline $\begin{array}{l}\text { (n=158) } \\
\text { Categoria profissional }\end{array}$ & $\begin{array}{c}\text { Sempre } \\
(\%)\end{array}$ & $\begin{array}{c}\text { Opções de resposta } \\
\text { Muitas vezes } \\
(\%)\end{array}$ & $\begin{array}{c}\text { Raramente } \\
(\%)\end{array}$ & $\begin{array}{c}\text { Nunca } \\
(\%)\end{array}$ \\
\hline $\begin{array}{l}\text { Médicos e pesquisadores } \\
\begin{array}{l}\text { Outros profissionais } \\
\text { de saúde nível superior }\end{array}\end{array}$ & 3,3 & 43,3 & 36,7 & 16,7 \\
$\begin{array}{l}\text { Outros profissionais } \\
\text { de nível superior }\end{array}$ & 5,3 & 25,0 & 58,3 & 8,3 \\
$\begin{array}{l}\text { Técnico/auxiliar de saúde } \\
\text { Outros técnicos/auxiliares }\end{array}$ & 24,2 & 29,4 & 35,3 & 29,4 \\
Total & 14,3 & 30,3 & 31,8 & 13,6 \\
\hline
\end{tabular}

Fonte: Pesquisa Gestão de Qualidade e Cultura em Organizações Públicas de Saúde. Escola Nacional de Saúde Pública, Fundação Oswaldo Cruz, 2000. Notas: $p$-valor $=0,058$.

Para a execução do teste, as colunas "sempre" e "muitas vezes" foram agregadas, mas ainda assim o número de células com freqüência esperada $<5$ atingiu 26,7\%. Considerando o peso de cada categoria, a distribuição de não-respostas foi maior no grupo Outros Técnicos e Auxiliares (8 missing); os demais grupos tiveram uma distribuição bastante similar entre si.

\section{Considerações finais}

A despeito do esforço de generalização efetuado nesse artigo, deve-se lembrar que as organizações, ainda que sejam do mesmo tipo - nesse caso, hospitalares -, possuem especificidades que as diferem umas das outras. O CPqHEC, por exemplo, é um hospital reconhecido por sua excelência, o qual, em inúmeros aspectos, não pode ser igualado a outros hospitais públicos brasileiros. O artigo procurou explorar pontos que tendem a ser comuns às organizações hospitalares, especialmente do setor público, tendo clareza de que os problemas discutidos possuem diferentes graus de intensidade em cada organização específica.

As propostas de reforma das estruturas do Estado, incorporadas à agenda política brasileira a partir do início da década de 90, têm inspirado diversas investigações sobre a administração pública brasileira e o funcionamento de suas organizações. A necessidade de mudanças orientadas para o alcance de maior eficiência e qualidade, assim como de maior accountability, implica a compreensão do ambiente interno e externo no qual as organizações efetivamente operam, ou seja, das representações, valores e práticas instituídas na organização específica e na sociedade em que se insere.

As organizações de saúde são espaços sociais por natureza conflituosos, nos quais a solidariedade e a coesão apresentam as mesmas fragilidades encontradas em outros ambientes de interação social. Diferentes grupos e indivíduos possuem expectativas e objetivos distintos, e as estratégias mobilizadas para alcançálos produzem, não raro, situações de conflito e contraditórias. Reconhecer a implausibilidade da eliminação dos conflitos não significa que se deva abrir mão de administrá-los, principalmente quando seus efeitos podem vir a se refletir na queda da eficiência e da qualidade dos serviços oferecidos aos usuários.

Nas organizações hospitalares, a heterogeneidade das categorias profissionais, aliada à distribuição de poder típica das organizações de especialistas, torna mais complexos os esforços de coordenação. Observou-se que alguns padrões de conflito são inerentes às organizações hospitalares, uma vez que expressam a distribuição de poder e prestígio que lhes é típica. A dicotomia entre o grupo central - médicos e pesquisadores -, no qual se funda a identidade da organização, e o conjunto de grupos periféricos, que dão suporte e viabilizam a realização das suas atividades, constitui a característica fundamental por meio da qual se pode compreender a estrutura que organiza os pa- 
drões de conflito. Essa oposição é englobante em relação a outras oposições possíveis, tais como médicos e pesquisadores versus outros profissionais de saúde de nível superior; áreafim versus área-meio; profissionais de nível superior versus técnicos e auxiliares. Aos grupos são conferidas diferentes posições de status de acordo com a proximidade que mantêm em relação ao grupo principal. Os fatores de aproximação são a qualificação em profissões/ocupações que integram a área de saúde e a escolaridade de nível superior. A categoria formada pelos técnicos e auxiliares da área-meio prescinde de ambos os atributos, daí o seu "desprestígio relativo" que, por sua vez, engendra nesse

\section{Agradecimentos}

Os autores agradecem a participação dos funcionários do Centro de Pesquisa Hospital Evandro Chagas na realização da pesquisa e, em especial, o apoio incondicional dado por sua Diretora, Dra. Keyla Marzochi.

\section{Referências}

BARBOSA, L., 1999. Igualdade e Meritocracia: A Ética do Desempenho nas Sociedades Modernas. 2a Ed. Rio de Janeiro: Editora Fundação Getúlio Vargas.

BOURDIEU, P., 1992. A Economia das Trocas Simbólicas. 3a Ed. São Paulo: Perspectiva.

COSTA, N.; RIBEIRO, J. M. \& SILVA, P. L. B., 2000. Reforma do Estado e mudança organizacional: Um estudo de hospitais públicos. Ciência \& Saúde Coletiva, 5:427-442.

DaMATTA, R., 2000. A Casa e a Rua: Espaço, Cidadania, Mulher e Morte no Brasil. 6a Ed. Rio de Janeiro: Rocco.

DUSSAULT, G., 1992. A gestão dos serviços públicos de saúde: Características e exigências. Revista de Administração Pública, 26:8-19.

ETZIONI, A., 1976. Organizações Modernas. 5a Ed. São Paulo: Pioneira.

FREIDSON, E., 1998. Renascimento do Profissionalismo. São Paulo: Edusp.

HAMILTON, D. M. \& BRITO, J., 1999. Análise Estratégica da Fundação Oswaldo Cruz Visando sua Qualificação como Agência Executiva. Relatório Institucional. Rio de Janeiro: Fundação Oswaldo Cruz. (mimeo.) grupo a produção de percepções negativas quanto às relações e ao ambiente de trabalho.

As questões analisadas com base nos dados obtidos mostram não apenas as opiniões e percepções sobre as relações e interações no interior da organização, mas refletem, ainda que em grau indeterminado, um conjunto de "representações sociais”, ou seja, de significados socialmente construídos e compartilhados. Tais representações certamente possuem uma ancoragem nas relações e interações empiricamente percebidas, mas as ultrapassam, na medida em que também são uma expressão de processos sócio-históricos mais amplos que se atualizam em diferentes esferas de interação.
MALIK, A. M., 1998. Gestão de Recursos Humanos. São Paulo: Universidade de São Paulo.

NOGUEIRA, R. P., 1994. Perspectivas da Qualidade em Saúde. Rio de Janeiro: Qualymark.

VAITSMAN, J., 1994. Flexíveis e Plurais: Identidade, Casamento e Família em Circunstâncias Pós-modernas. Rio de Janeiro: Rocco.

VAITSMAN, J., 2000. Cultura de organizações públicas de saúde - Notas sobre a construção de um objeto. Cadernos de Saúde Pública, 16:847-850.

VAITSMAN, J., 2001. Gerencialismo, cultura e expectativas entre servidores públicos de saúde. Revista de Administração Pública, 35:29-48.

VELHO, G., 1999. Individualismo e Cultura: Notas para uma Antropologia da Sociedade Contemporânea. 5a Ed. Rio de Janeiro: Zahar.

Recebido em 3 de maio de 2001

Versão final reapresentada em 8 de novembro de 2001

Aprovado em 28 de janeiro de 2002 